\title{
ENSAIO DE COMBATE AO "ACARO DA FALSA FERRUGEM", PhyZlocoptruta oleivora (ASHM., 1879), COM GRANULADOS NO SOLO *
}

J.C. OLIVEIRA FILHO **, J.C. CARVALHO ** S. TAVARES $* *, J . R$. MARCONATO $* *$ R. FAGAN **, H.C: BRUNELLI JÚNIOR ** F.A.M. MARICONI ***

\section{RESUMO}

Com o objetivo de combate ao ācaroda fal sa ferrugem, Phyzlocoptruta oleivora foi realizado o presente trabalho, com a incorporação de granulados no solo. 0 pomar experimental era formado de "Laranjeiras Bahianinha", de 15 a 18 anos de idade.

Os granulados foram aplicados no solo, em dois sulcos rasos, paralelos e opostos, sob a saia das plantas. Os granulados e as quantidades dos produtos comerciais, por planta, foram: A) etoprope G $10 \%, 80 \mathrm{~g}$; B) carbossulfano G $5 \%, 80 \mathrm{~g}$;

* Entregue para publicação em 14/11/1980.

** Departamento de Zoologia, E.S.A. "Luiz de Queiroz", USP. Bolsistas.

*** Departamento de Zoologia, E.S.A. "Luiz de Queiroz", USP. 
C) isazofós G $10 \%, 70 \mathrm{~g}$; D) carbossulfano $G 5 \%$, $50 \mathrm{~g}$; E) fensulfotion $G 5 \%$, $400 \mathrm{~g} ; \mathrm{F}$ ) fensulfotiom G 5\%, 250g; G) testemunha.

Foram realizadas, em laboratório, contagens aos $0,22,36,50$ e 88 dias. Os resultados foram completamente negativos.

\section{INTRODUÇÃO}

o ácaro da falsa ferrugem, Phylzocoptruta oleivora (Ashm., 1879) é uma das principais pragas das plantas cítricas (muitos a julgam como sendo a principal).

Assim, têm sido relativamente comuns os trabalhos de combate ao citado ácaro, principalmente por pulverização de acaricidas e de inseticidas-acaricidas. Mais recentemente, apareceram trabalhos em que são usados granulados no solo, que veremos a seguir. MARICONI (1977) anuncia o início do uso de granulados sistêmicos no solo. SANTOS et alii (1977) dão a conhecer excelentes resultados de combate mediante o uso do aldicarbe granulado a $10 \%$, à razão de $100 \mathrm{~g}$ e $200 \mathrm{~g}$ por 1 a ranjeira (não há, entretanto, diferença significativa nos resultados das duas dosagens). MARICONI et alii (1978) obtém otimos resultados com o aldicarbe, à razão de $400 \mathrm{~g}$ do granu lado por planta (este trabalho deveria ter saỉdo antes do anterior). FAGAN et alii (1978) experimentam, sem resultados positivos, o protoato e o monocrotofós. O aldicarbe, à razão de $100 \mathrm{~g}$ do granulado por árvore, foi incorporado ao solo em circulo completo e em dois sulcos rasos, paralelos e opostos: os resultados mostram que não há diferença significativa entre os métodos. NASCIMENTO \& ZEM (1978) usam, na Bahia, o aldicarbe e o oxamil, obtendo resultados notáveis. BRUNELLI JR. et alii (1978) usam o oxamil e o fensulfotiom, bem como - aldicarbe (100 g e $40 \mathrm{~g}$ por planta), sendo a dosagem alta, - tratamento padrão; a dosagem baixa revelou resultados semelhantes aos da alta.

0 presente trabalho teve como objetivo verificar a ação de vários outros granulados sobre o ácaro. 


\section{MATERIAIS E MÉTODOS}

Local: o trabalho experimental foi realizado em pomar da "Chācara das Paineiras", em Limeira, Estado de São Paulo, de propriedade do sr. Guilherme Hebling.

Laranjal: variedade "Bahianinha", de 15 a 18 anos de idade. As plantas eram muito vigorosas, com as seguintes dimensões médias: 4,50 m de altura, tronco com 0,78 m de circunferência (a $10 \mathrm{~cm}$ do solo) e diâmetro máximo da copa (entre fileiras), de $5,30 \mathrm{~m}$. Espaçamentos: $6 \mathrm{~m}$ nas fileiras e $7 \mathrm{~m}$ entre fileiras (portanto, 238 laranjeiras por hectare).

Tratamentos: adotou-se o método de blocos casualizados para sete tratamentos com quatro repetições. Havia, portanto, 28 canteiros ou parcelas e cada um deles abrangia duas laran jeiras. Plantas não tratadas foram deixadas entre os cantei= ros, como barreira.

$\mathrm{Na}$ Tabela 1 estão relacionados os tratamentos, formula ções comerciais, consumo dos defensivos etc. (somente foram usados granulados).

Granulado por planta: a pesagem dos granulados foi fei ta em laboratório; a quantidade necessária para cada uma das plantas foi levada para o campo, em saquinho rotulado. Assim, num mesmo tratamento, cada laranjeira recebeu o mesmo peso de granulado.

O granulado de cada saquinho foi colocado em dois sulcos rasos (5 a $10 \mathrm{~cm}$ de profundidade), paralelos e opostos, situados sob a projeção da copa; logo após, os sulcos foram fechados.

Aplicação e contagens: realizou-se a aplicação em 18 de dezembro de 1978. As coletas de folhas, para as contagens de ácaros, foram cinco: a inicial, realizada no dia da aplicação e as outras, em 09 e 23 de janeiro (após 22 e 36 dias da aplicação), em 06 de fevereiro (após 50 dias) e, finalmen te, em 16 de março de 1979 (depois de 88 dias da aplicação dos granulados). As contagens foram feitas, com o uso de lupas de mesa e aumento de 25 vezes, em área circular, na pá- 


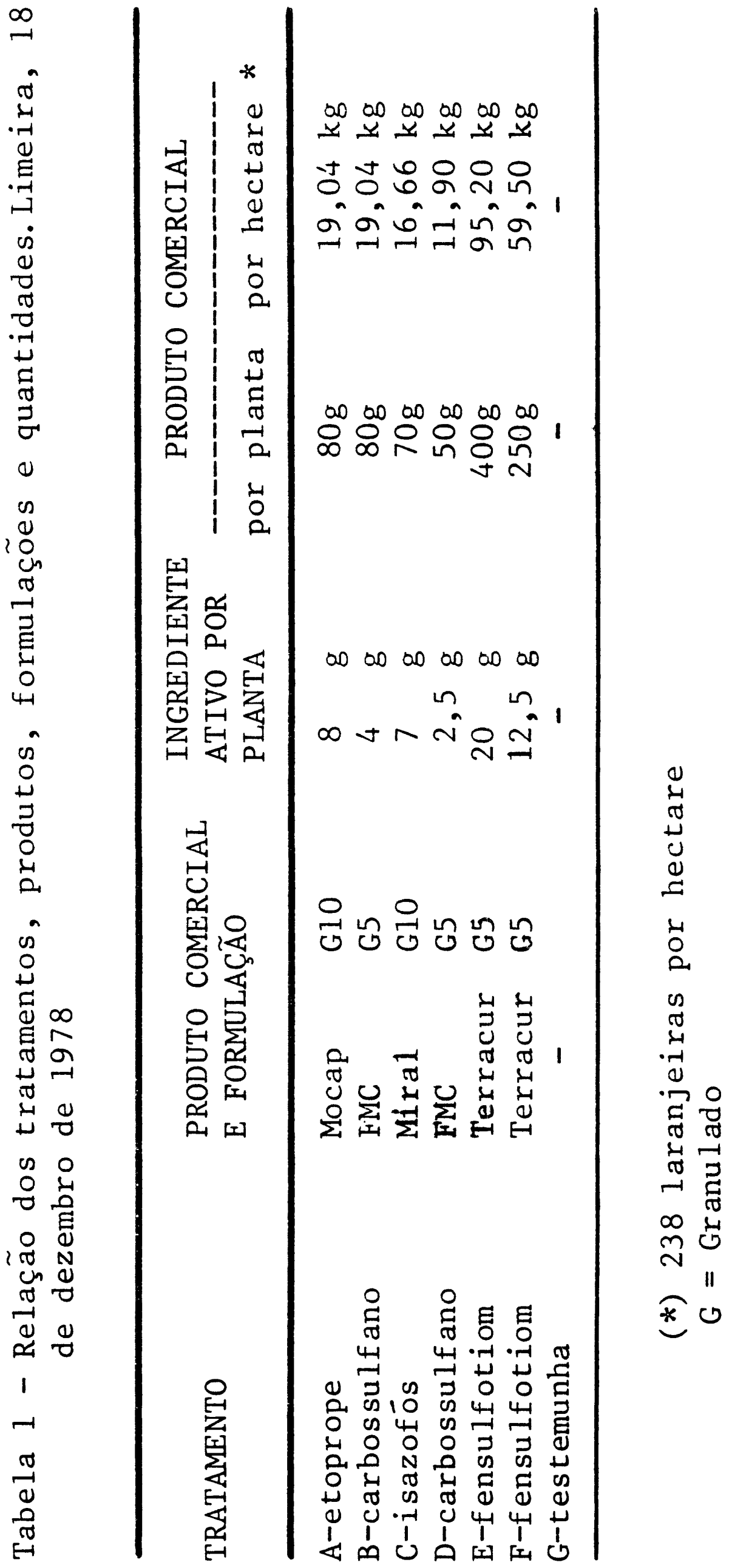




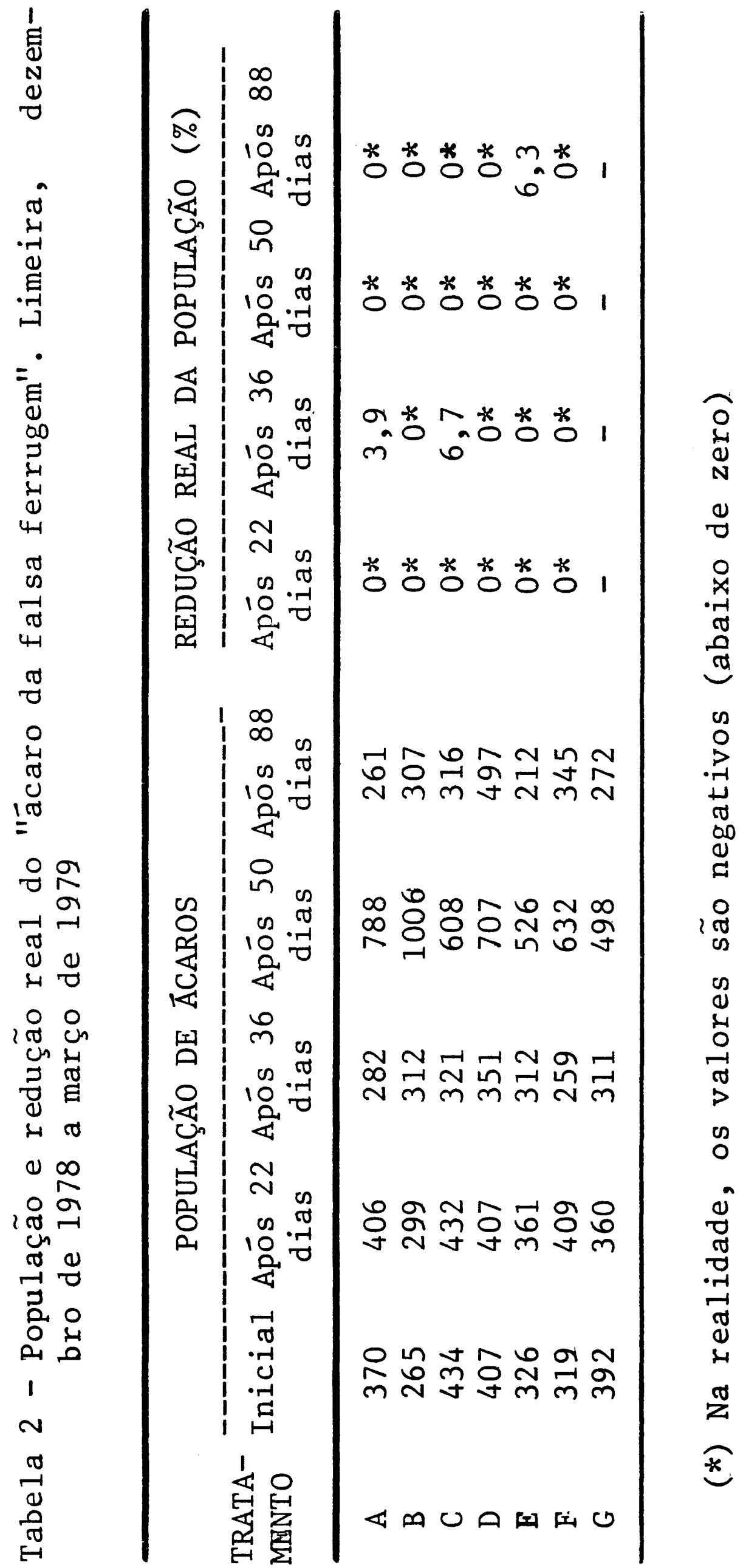


gina inferior, localizada na base da folha, de modo que a nervura principal a cortasse em duas partes aproximadamente, iguais. No dia da aplicação, a camada superficial do solo es tava seca, mas poucos dias depois choveu bastante.

Amostragens: para cada um das cinco contagens, retiraram-se 20 folhas de cada laranjeira (portanto, 40 por cantei ro e 160 por tratamento). As folhas foram coletadas em toda a volta das plantas, colocadas em saquinhos plásticos, individuais para cada canteiro, e levadas para o laboratório em caixa de isopor.

Cálculos estatísticos: não realizados, pois os granula dos fracassaram totalmente em combater o ácaro.

\section{RESULTADOS E DISCUSSÃO}

Contagens de ácaros em folhas coletadas aos 22, 36, 50 e 88 dias da aplicação mostram, quando estudadas com as obti das no dia da aplicação, que nenhum produto teve atuação positiva. Portanto, não se deve usar nenhum desses produtos.

\section{CONCLUSÕES}

0 etoprope, carbossulfano (2 dosagens), isazofós e fensulfotiom (2 dosagens) não combatem o âcaro da falsa ferrugem.

\section{SUMMARY}

CITRUS RUST MITE CONTROL ON ORANGE TREES WITH

GRANULAR INSECTICIDES APPLIED IN THE SOIL.

Granular insecticides used in the soil were evaluated for the control of the citrus rust mite, Phylzocoptruta oleivora, on orange trees. The application consisted of two parallel lines in the soil per tree.

The treatments and the active ingredients per tree 
were as follows: A) etoprop, $8 \mathrm{~g}$; B) carbosulfan, $4 \mathrm{~g}$; C) isazophos, $7 \mathrm{~g}$; D) carbosulfan, 2.5; E) fensulf othion, $20 \mathrm{~g}$; F) fensulfothion, $12.5 \mathrm{~g} ; \mathrm{G})$ check.

Counts of the mites were made in laboratory at the day of application and 22,36,50, and 88 days after the application (Table 1). None of the granular pesticides gave positive results (Table 2).

\section{LITERATURA CITADA}

BRUNELLI JR., H.C.; CARVALHO, J.C.; OLIVEIRA FILHO, J.C.; FA GAN, R.; SANTOS, B.M. ; AMORIM FILHO, L.A.; MARICONI, F.A. M., 1978. Granulados sistêmicos incorporados ao solo no combate ao ácaro Phyllocoptruta oleivora (Ashm., 1879) em laranjeiras adultas, 0 Solo, Piracicaba, 70(2): 15-19.

FAGAN, R.; AMORIM NETO, L.A.; BRUNELLI JR., H.C.; SANTOS, B. M.; MARICONI, F.A.M.; OLIVEIRA FILHO, J.C.; CARVALHO, J. C.; FRANCO, J.F., 1978. Combate ao ácaro PhyZZocoptruta oleivora (Ashm., 1879), em laranjeiras adultas, com a aplicação de sistêmicos no solo e na parte aérea. o Solo, Piracicaba, $70(1): 30-35$.

MARICONI, F.A.M., 1977. Evolução no combate a algumas pragas dos citros, especialmente os ácaros. Anais IV Encontro Na cional Citricultura, 21 a 24 de agosto, Aracaju, Sergipe, p. 153-163.

MARICONI, F.A.M.; TARDIVO, J.C.; SANTOS, B.M.; DIONISIO, A.; BRUNELLI JR., H.C.; AMORIM NETO, L.A.; FAGAN, R. 1978. Combate experimental ao ácaro Phyllocoptruta oleivora (Ashm., 1879) com inseticidas em pulverização e um granulado sistêmico incorporado ao solo. Rev. Agric,, 53(1-2): 81-85.

NASCIMENTO, A.S:; ZEM, A.C., 1978. Controle do ácaro da "fer rugem" PhylZocoptruta oleivora (Ashm., 1879) em citros com sistêmicos granulados. Rev. Brasil. Fruticultura, Cruz das Almas, 1(2): 71-75. 
SANTOS, B.M.; BRUNELLI JR., H.C.; FAGAN, R.; AMORIM NETO, L. A.; TARDIVO, J.C.; DIONISIO, A.; FRANCO, J.F.; MARICONI, F.A.M., 1977. Combate experimental ao "ácaro da falsa fer rugem da laranjeira" com sistêmicos aplicados no solo. $\overline{0}$ Solo, Piracicaba, 69(2): 32-36. 